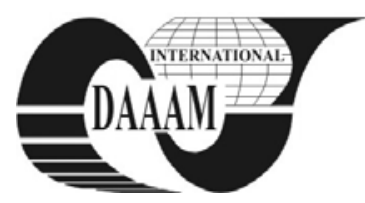

Annals of DAAAM for 2011 \& Proceedings of the 22nd International DAAAM Symposium, Volume 22, No. 1, ISSN 1726-9679 ISBN 978-3-901509-83-4, Editor B. Katalinic, Published by DAAAM International, Vienna, Austria, EU, 2011 Make Harmony between Technology and Nature, and Your Mind will Fly Free as a Bird Annals \& Proceedings of DAAAM International 2011

\title{
MODERN PRODUCTION IN FOOD INDUSTRY - OPENED CHALLENGE FOR THE FUTURE
}

\author{
SAHAROV, N[atalia]
}

\begin{abstract}
This study represents a judicial approach over heat debated theme relative to concern on the safety of genetically modified (GM) food. As adverse effect of these modern production can appear in a long time it is compulsory to initiate and draw an adequate legal framework regarding, especially liability and compensation.

Key words: genetically modified organism, plants and food GMO, GMP, legislative regulations, adverse effects, damages,
\end{abstract} liability.

\section{INTRODUCTION}

Food industry and society in general, is confronting lately with consequential aspects of what conception of genetically modified organism and plants (GMO, GMP) means.

Among others controversial aspects, there are several analyzed in this study: existence of legislative regulations in this area, public perception on these products, connection between theory and practice.

Genetic modification, also known as "genetic engineering" or "recombinant-DNA technology" was first applied in the 1970 's. There is approximately 15 years since the introduction of genetic modification in food. However only after 5 years since adding the new GM products to the existing list of food there was a signal to alert the lack of published information concerning safety of GM foods. Indeed, there were some studies in this area but not performed by the biotechnology companies that produce/commercialize these products.

According to review on the safety assessment of genetically modified plant on period 2000-2006, if data on toxicological assessment of GM foods/plants existed, these had not been reported in scientific journals, and therefore, they were not available to the general scientific judgment. On the period 2006-2010 was noticed a substantial advance in comparison to previous period but even if number of studies increased they concern only some of GM products and moreover there is still controversial debate on safety of analyzed GM products (Domingo \& Bordonaba, 2011).

Besides scientific community, mass-media and public opinion, in general, didn't build a certain perception over these products, yet. The situation can be understood because despite a large amount of public attention we are still unaware of the advantages and disadvantages of GM products. Moreover, the adverse effect of genetically modified foods if they exists or non-risk consume on human health will be available only after more experiments based on more longer terms.

Without intention to anticipate the results, even there are significant number of voices that are militating against commercializing and consuming of these products, it is necessarily to have an adequate legislation ready to face these risks, to protect public interests of society such as human life and health, animal health and welfare, environment and consumer interests, to avoid discrepancies between practice and theory.

\section{EU LEGAL FRAMEWORK REGARDING GM PRODUCTS}

The application of genetic technology apparently seems to be strictly regulated by an extensive legal framework on GMOs established in European Union since the early 1990s.

The two main legal instruments in EU legislation on GMO are: Directive 2001/18/EC on the deliberate delease ofGMOs and, Regulation (EC) No 1829/2003 on genetically modified food and feed.

Even if the provisions of Directive 2001/18 are not exactly soft, because its requires complex procedures for the release and marketing of GMOs based on a scientific risk assessment, establish a limited period of 10 years for market authorization, recognizes to member states the right of taking appropriate measures to avoid the unintended presence of GMOs in other products, liability has not been seen in the context of the measures looking to avoid any adverse and prejudicial consequences. Therefore, is developed an intense system of legal measures to prevent the release and marketing of non-safe GM products but, is neglected or even missing a system that will provide a remedy for damages caused by these products.

In the same context, Article 30 of Regulation no 1829/2003 stipulates that is necessary to establish harmonized procedure for risk assessment and authorization that are efficient, timelimited and transparent, and criteria for evaluation of the potential risks arising from genetically modified foods and feed. Further in Article 5 entitled Application for authorization, are listed the documents that shall accompany the application. Letter $(\mathrm{k})$ of the mentioned article requires a proposal for postmarket monitoring regarding use of the food for human consumption, only where appropriate. Considering the possibility that adverse effect of genetically modified products can appear only after a long term since consumption, it would be recommendable to transform this proposal for post-market monitoring in a mandatory requirement. Other words, the potential risk arising from genetically modified products should be monitoring not only during the procedure of authorization but after as well, at least a reasonable period of time. This requirement cannot be neglected especially when overwhelming consensus about safety of GM food consumption is missing and there are studies and experiments revealing that the current safety assessments are incompetent to even identify most of the health risks for humans, not talking about potentially disastrous effects on the environment (Smith, 2009).

The Regulation No $1829 / 2003$ avoid the possibility of confusion between the GMOs products and similar conventional products by requiring compulsory a labeling that should include objective information to the effect that a food or feed consists of, contains or is produced from GMOs, information about any characteristics or property which renders a food or feed different from its conventional counterpart, intended use of the food or feed and health implications for certain sections of the populations, as well as any characteristics or property which gives rise to ethical or religious concern. Clear labeling meets the demands expressed 
in numerous surveys by a large majority of consumers, facilitates informed choice and precludes potential misleading of consumers as regards methods of manufacture or production. There is no doubt that exigency of the regulations leave the freedom of choice to consume or not consume these products.

The situation is more dramatically in the countries not members of EU that didn't develop a law for labeling or having this requirement doesn't mention punitive actions. This makes labeling exercises almost a figurative gesture with no real legal deterrent.

Anyhow the freedom of choice recognized to EU consumers doesn't absolve from liability for the damages resulting from genetically modified products. Moreover the freedom of choice belongs only to consumer because the member states of EU should follow its legislation. In other words, EU regulations supersede national regulations.

So, following the EU recommendations, national legislation has to develop a special regulation on this form of liability.

\section{SPECIAL LIABILITY FOR DAMAGES CAUSED BY GM PRODUCTS}

Human safety under GM food consumption has been a matter of grave concern. This concern increased after first signs of adverse effects appeared. For example, after GM soy was introduced in the UK, cases of allergies went up (Rodgers, 2003).

Under these alarming circumstances we want to find out if there are regulated appropriate legal measures to avoid, prevent and even repair the potential damages caused by GM food consumption.

We wonder if the lack of special regulations can be covered by provisions of civil Law. Indeed, civil Law of most member states contains provisions regarding liability in general, and even a few provisions regarding liability for some kinds of damages arising from GM products. We consider that it is unlikely to get an adequate compensation/reparation of these potential damages only on civil Law bases. The arguments to maintain this opinion are briefly presented bellow.

First of all, an overview of conditions required for engaging the civil liability, i.e. damage, cause, causal link, in some cases fault, reveals the fact, that in the specific area of liability for damages caused by GM products, they are not that simple to be applied on. It is obvious that condition of causal relationship and even fault are very hard, if not impossible to be proved without a special settlement in this area. This statement is based on a comparative analysis of existing legal systems. So, the liability regime can be fault-based, strict or absolute or nonfault based. Therefore, even if the fault condition is excluded, laying the liability on guaranteed protection of consumer, it is still can be rough to prove causal relationship between GM food consumption and health damages.

This is just one of many arguments that could support our demarche for adoption, implementation and development of special legal provisions in this specific area of liability. This is not a one day work or a one person work. There are a lot of issues that should be stipulated. Among them, as we shown previously, it is necessarily to regulate, on whose shoulders lays the burden of proof.

Sustaining our demarche we are strongly convinced that difficulty of proof cannot justify the lack of legal framework on this form of liability, and consequently the impossibility to file an action, because any damages caused to a person by another should enable the victim to a reparation or equitable compensation.

In our research we identified that there are exist in several countries, regulations regarding some GM product, like crops for example, which shows useful solutions (Koch, 2007).

Thereby, to easy up the burden of proof, the special liability regime for damage caused by GM products can be established on a presumption of causation. The nature of presumption - absolute or relative - is essential for this kind of regulations, because an absolute presumption cannot be rebut by producing counterevidence while an relative presumption can be rebut by proving evidence that there is no connection between GM food consumption and existing damages.

Non-fault based liability regime permit to avoid some of the arbitrariness of the liability system i.e. compensation could be determined on the basis of objective criteria of causal contribution, rather than on the basis of subjective elements of fault.

There is an open possibility to set up compensation funds, whether public or private or a combination of both, that would provide at least some compensations for damages caused by GM foods. In both cases is mandatory to draw the criteria for determining the amount of compensation. Because of novelty and unknown nature of potential adverse effect of GM food consumptions, isn't equitable to fix a financial limit to this special liability, even if such limits are recommendable and regulated by member states legislation regarding to other forms of civil liability.

We intend to continue our research by analyzing advantages and disadvantages of existing legal provisions in this area, by making proposal to adopt new ones, which finally will contribute to development of a unique system applicable within EU.

\section{CONCLUSION}

The uncertainties about their direct health and environmental impacts, genetically modified products may contain potential risks. Under these circumstances the priority shall be directed to the adoption of adequate legislation for the potential situation of discovering, as yet unknown, long-term risks. The regulations, we are militating for should cover these situations and ensure liability for damages and provide compensation. Otherwise, the heat debate about possible impacts of genetically modified organisms and plants especially on human health and in general on environment, or human society, on genetic diversity will remain without practical consequences in case of proving this effect.

\section{ACKNOWLEDGEMENTS}

This work was supported by the strategic grant POSDRU/ CPP107/DMI1.5/S/78421, Project ID78421 (2010), co-financed by the European Social Fund within the Sectorial Operational Program Human Resources Development 2007 - 2013

\section{REFERENCES}

Domingo, J. L., Bordonaba, J. G., (2011). A literature review on the safety assessment of genetically modified plant, Environment International 37 (2011), p. 734-742, ISSN 0160-4120,

Koch, B. A., Liability and compensation schemes for damage resulting from the presence of genetically modified organisms in non-GM crops, European Centre of Tort and Insurance Law, Research Unit for European Tort Law Austrian Academy of Sciences, April 2007,

Rodgers, Ch. P., (2003). Liability for the release of GMOs into environment: exploring the boundaries of nuisance, Cambridge Law Journal, 62(2) July 2003, printed in Great Britain, pp. 371-402, ISSN 0008-1973 EISSN 1469-2139.

Smith, M., (2009). Genetic modification "inherently unsafe". An interview with Jeffrey Smith, Genetic modification \& quot; inherently unsafe\&quot, Briar patch, Jan/Feb 2009, 38, 1; ProQuest Central pg.18;

JRC Scientific and Technical Reports, Plan, D., Guy Van den Eede - The EU legislation on GMOs. An overview, 2010, Available from: http://mbg.jrc.ec.europa.eu/home/documents/2010-08-12 